\section{Pain score assessment in babies undergoing laser treatment for retinopathy of prematurity under sub-tenon anaesthesia}

ES Novitskaya'1, V Kostakis ${ }^{1}$, SC Broster ${ }^{2}$ and LE Allen ${ }^{1}$

\begin{abstract}
Purpose To assess the tolerability and outcomes of laser treatment for retinopathy of prematurity (ROP) under sub-tenon anaesthetic with oral or rectal sedation using a reliable, multidimensional, and internationally accepted tool for assessment of neonatal pain.

Methods Sixty-two babies have had ROP laser treatment in our neonatal unit in the 7-year interval between 1 March 2005 and 28 February 2012; 44\% (27 of the 62) were performed using sub-tenon anaesthesia. Pain scores were routinely assessed using the Neonatal Pain Agitation and Sedation Scale (N-PASS) every $10 \mathrm{~min}$ during laser treatment. The outcome and requirement for re-treatment in this group was compared with that in the intravenous sedation group. Results Pain scores were available in 19 of the 27 babies treated under sub-tenon anaesthesia. The mean pain score during treatment was 2.7 ( $\mathrm{SD} \pm 1.7$, range 0.5-6.2). There was no statistically significant correlation between the mean pain score and duration of treatment (Spearman correlation coefficient $(\rho)=0.31 ; P=0.09$ ), number of laser burns ( $\rho=0.32 ; P=0.09$ ), or post-menstrual age of the baby at the time of treatment $(\rho=0.38 ; P=0.052)$. Treatments performed under sub-tenon anaesthesia were as successful as those performed under intravenous sedation. The mean pain scores during laser treatment under sub-tenon anaesthesia in our study were lower than those previously reported during ROP screening or heel-stick procedure.
\end{abstract}

Conclusion Our study demonstrated that sub-tenon anaesthesia with oral or rectal sedation provides sufficient pain control for laser treatment for ROP without the need or risks of intravenous sedation and intubation. Eye (2013) 27, 1405-1410; doi:10.1038/eye.2013.205; published online 20 September 2013

Keywords: retinopathy of prematurity; ROP; anaesthesia; sub-tenon; pain score; N-PASS

\section{Introduction}

The portability of modern lasers has enabled treatment for retinopathy of prematurity (ROP) to evolve from a procedure performed under general anaesthesia in an operating theatre to a treatment performed in the neonatal unit, with the baby under the supportive care of the neonatologist. Despite this development, a recent survey reported that among UK ophthalmologists who regularly treat ROP, $50 \%$ use general anaesthetic and 35\% use intravenous sedation with intubation; only two consultants (3\%) regularly use sub-tenon anaesthesia with oral or rectal sedation. ${ }^{1}$ This technique is used more widely in developing countries, possibly because of limited access to paediatric anaesthetists. ${ }^{2}$ Sub-tenon anaesthesia avoids the considerable systemic risks of re-intubation and may permit treatment to be performed as a day transfer from referring neonatal units.

Although the cardiorespiratory effects of laser treatment for ROP under sub-tenon anaesthesia have been evaluated previously, the acceptability
${ }^{1}$ Ophthalmology

Department, Cambridge University Hospitals NHS Foundation Trust, Cambridge, UK

${ }^{2}$ Neonatal Department, Rosie Maternity Hospital, Cambridge, UK

Correspondence: ES Novitskaya, Ophthalmology Department, Cambridge University Hospitals NHS Foundation Trust, Hills Road, 260 Cherry Hinton Rd, Cambridge CB1 7AU, UK. Tel: + 44 (0)7969048873; Fax: + 44 (0)14080363693 E-mail: elena.novitskaya@ gmail.com

Received: 9 November 2012 Accepted in revised form: 12 July 2013

Published online: 20 September 2013 
of the technique in terms of pain control has not. 3,4 The aim of this study was to assess the tolerability and outcomes of laser treatment for ROP under sub-tenon anaesthetic with oral or rectal sedation using a reliable multidimensional and internationally accepted tool for assessment of neonatal pain. ${ }^{5,6}$

\section{Methods}

The ROP screening protocol in our level 3 neonatal unit follows the current Royal College of Ophthalmologists Guidelines. ${ }^{7}$ Treatment and outcome data are routinely collected and audited. We started using sub-tenon anaesthesia with oral or rectal sedation as an alternative to intravenous sedation for laser treatment in March 2005. When possible (determined by the staffing levels on the neonatal unit), we have collected pain scores using the Neonatal Pain Agitation and Sedation Scale (N-PASS) system during laser treatment using sub-tenon anaesthesia. The need for treatment was based on the criteria in the Early Treatment for Retinopathy of Prematurity (ETROP) study. ${ }^{8}$ All babies were assessed by an experienced neonatologist before treatment. Suitability for sub-tenon anaesthesia with either oral or rectal sedation was based on the following: continuous positive air pressure (CPAP) of $6 \mathrm{~cm} \mathrm{H}_{2} \mathrm{O}$ or less, oxygen requirement of $40 \%$ or less, and no desaturations or bradycardias requiring intervention in the previous $48 \mathrm{~h}$. Babies who were already intubated, or who were considered to be too unstable to tolerate treatment under oral or rectal sedation with sub-tenon anaesthesia underwent laser treatment using intravenous sedation with endotracheal intubation.

\section{Oral or rectal sedation and analgesia with sub-tenon regional anaesthesia}

Babies having sub-tenon anaesthesia were fasted for three hours and given oral or rectal chloral hydrate and paracetamol $30 \mathrm{~min}$ before the treatment. The oral doses of chloral hydrate and paracetamol were 50 and $10 \mathrm{mg} / \mathrm{kg}$, and the rectal doses 50 and $20 \mathrm{mg} / \mathrm{kg}$, respectively. The pupils were dilated with cyclopentolate $0.5 \%$ and phenylephrine $2.5 \%$ drops instilled 60 and $30 \mathrm{~min}$ before the treatment. Babies already having CPAP-assisted ventilation before treatment were kept on this system with the nasal mask changed to nasal prongs to improve access to the eyes. Supplemental oxygen delivered by nasal cannula was used for the other babies during the treatment.

Although no neonatologist or neonatal anaesthetist was present during the treatment, the location of the treatment room within the neonatal unit ensured a rapid response in case of prolonged desaturation or concerns of baby's tolerance of the procedure. The neonatal nurse closely observed the cardiovascular and oxygen saturation monitors and titrated the concentration of supplemental oxygen to the baby's response. The baby was swaddled and given oral $24 \%$ sucrose solution just before and at intervals during the laser treatment. A pacifier was used if accepted by the baby. When possible a second health-care professional (nurse or medical trainee) was present to facilitate recording of the N-PASS score.

After administration of topical proxymetacaine $0.5 \%$, a neonatal speculum was inserted and a small, infero-nasal conjunctival and tenon capsule incision was made with Westcott scissors to gain access to the sub-tenon space. A disposable 23-gauge blunt tipped cannula (we used a nucleus hydrodissection cannula) was introduced and $0.5 \mathrm{ml}$ of $0.5 \%$ lignocaine was delivered into the subtenon space. Laser treatment was then performed using an indirect ophthalmoscope-mounted diode laser (SLx, Iris Medical Instruments, Mountainview, CA, USA) and a 28-dioptre lens. This sequence was then repeated on the other eye.

\section{Pain score assessment}

The N-PASS is a widely used system for assessing pain scores in the neonates. The N-PASS system includes physiological (heart rate, respiratory rate, blood pressure, and oxygen saturation) and behavioural indicators (crying/irritability, behaviour/state, facial expression, and extremities/tone). As premature infants have a limited ability to display and maintain behavioural or physiological manifestations of pain the N-PASS tool adjusts pain score on the basis of gestational age (points are added to approximate the normal response of a full-term infant). The score ranges from 0 to 10 and reflects pain and agitation (Table 1).

Where possible, the N-PASS agitation score was reported by the nurse supporting the baby and recorded by a second health-care professional before the start of the treatment (baseline) and every 10 min during the procedure.

\section{Statistical analysis}

Mann-Whitney $U$-test was used to compare the difference in the parameters between the groups of babies treated under sub-tenon anaesthesia with sedation and the group of babies treated under GA. The correlation between the pain score and PMA, number of laser burns and duration of treatment was calculated using Spearman rank-order correlation coefficient $(\rho)$. A $P$-value of $\leq 0.05$ was considered to be statistically significant. 
Table 1 Neonatal Pain/Agitation and Sedation Scale (N-PASS)

\begin{tabular}{|c|c|c|c|c|c|}
\hline \multirow{2}{*}{$\begin{array}{l}\text { Assessment } \\
\text { criteria }\end{array}$} & \multicolumn{2}{|r|}{ Sedation } & \multirow{2}{*}{$\frac{\text { Sedation/pain }}{0 / 0}$} & \multicolumn{2}{|c|}{ Pain/agitation $^{\mathrm{a}}$} \\
\hline & -2 & -1 & & 1 & 2 \\
\hline $\begin{array}{l}\text { Crying } \\
\text { irritability }\end{array}$ & $\begin{array}{l}\text { No cry with } \\
\text { painful stimuli }\end{array}$ & $\begin{array}{l}\text { Moans or cries minimally } \\
\text { with painful stimuli }\end{array}$ & $\begin{array}{l}\text { No sedation/ } \\
\text { no pain signs }\end{array}$ & $\begin{array}{l}\text { Irritable or crying at } \\
\text { intervals } \\
\text { Consolable }\end{array}$ & $\begin{array}{l}\text { High-pitched or silent- } \\
\text { continuous cry } \\
\text { Inconsolable }\end{array}$ \\
\hline Behaviour state & $\begin{array}{l}\text { No arousal to } \\
\text { any stimuli } \\
\text { No spontaneous } \\
\text { movement }\end{array}$ & $\begin{array}{l}\text { Arouses minimally to } \\
\text { stimuli } \\
\text { Little spontaneous } \\
\text { movement }\end{array}$ & $\begin{array}{l}\text { No sedation/ } \\
\text { no pain signs }\end{array}$ & $\begin{array}{l}\text { Restless, squirming } \\
\text { Awakens frequently }\end{array}$ & $\begin{array}{l}\text { Arching, kicking } \\
\text { Constantly awake or } \\
\text { Arouses minimally/no } \\
\text { movement (not sedated) }\end{array}$ \\
\hline $\begin{array}{l}\text { Facial } \\
\text { expression }\end{array}$ & $\begin{array}{l}\text { Mouth is lax } \\
\text { No expression }\end{array}$ & $\begin{array}{l}\text { Minimal expression with } \\
\text { stimuli }\end{array}$ & $\begin{array}{l}\text { No sedation/ } \\
\text { no pain signs }\end{array}$ & $\begin{array}{l}\text { Any pain expression } \\
\text { intermittent }\end{array}$ & $\begin{array}{l}\text { Any pain expression } \\
\text { continual }\end{array}$ \\
\hline $\begin{array}{l}\text { Extremities } \\
\text { tone }\end{array}$ & $\begin{array}{l}\text { No grasp reflex } \\
\text { Flaccid tone }\end{array}$ & $\begin{array}{l}\text { Weak grasp reflex } \\
\downarrow \text { muscle tone }\end{array}$ & $\begin{array}{l}\text { No sedation/ } \\
\text { no pain signs }\end{array}$ & $\begin{array}{l}\text { Intermittent clenched toes, } \\
\text { fists or finger splay } \\
\text { Body is not tense }\end{array}$ & $\begin{array}{l}\text { Continual clenched toes, } \\
\text { fists, or finger splay } \\
\text { Body is tense }\end{array}$ \\
\hline $\begin{array}{l}\text { Vital signs } \mathrm{HR} \text {, } \\
\mathrm{RR}, \mathrm{BP}, \mathrm{SaO}_{2}\end{array}$ & $\begin{array}{l}\text { No variability } \\
\text { with stimuli } \\
\text { Hypoventilation } \\
\text { or apnoea }\end{array}$ & $\begin{array}{l}<10 \% \text { Variability from } \\
\text { baseline with stimuli }\end{array}$ & $\begin{array}{l}\text { No sedation/ } \\
\text { no pain signs }\end{array}$ & $\begin{array}{l}\uparrow \uparrow 10-20 \% \text { from baseline } \\
\mathrm{SaO}_{2} 76-85 \% \text { with } \\
\text { stimulation-quick } \\
\text { recovery } \uparrow\end{array}$ & $\begin{array}{l}\uparrow \uparrow 20 \% \text { from baseline } \\
\mathrm{SaO}_{2} \leq 75 \% \text { with } \\
\text { stimulation-slow } \\
\text { recovery } \uparrow \\
\text { Out of sync with vent }\end{array}$ \\
\hline
\end{tabular}

${ }^{\mathrm{a}}$ The pain score is adjusted in premature infants according to gestational age categories: +3 for $<28$ weeks gestation; +2 for $28-31$ weeks gestation; +1 for 32-35 weeks gestation.

\section{Results}

\section{Treatment for ROP}

Laser treatment for ROP was performed in 62 babies (124 eyes), $5.9 \%$ of the total number of newborns screened for ROP between March 2005 and March 2012. The neonatologists considered 35 of the 62 babies (56\%) unsuitable for treatment using sub-tenon anaesthesia due to cardiorespiratory instability. The other 27 (44\%) underwent laser treatment using sub-tenon anaesthesia in combination with oral or rectal sedation and analgesia. All laser treatments using sub-tenon anaesthesia were primarily performed by consultant (LEA), 1 of the 35 cases having intravenous sedation was treated by a subspecialty Fellow. The proportion of babies treated with sub-tenon anaesthesia increased from $8 \%$ (1 of the 13) in 2005 to $75 \%$ (9 of the 12) in 2009 and then remained the preferred mode of anaesthesia for laser treatment (Figure 1). The mean post-menstrual age (PMA), birth weight (BW), PMA at treatment, zone, and stage of ROP of all treated subjects are shown in Table 2. There was no significant difference between the treatment groups in ROP stage or zone, mean gestational age or mean PMA at treatment but the birth weight was higher in the subtenon anaesthesia group $(P=0.001)$.

All babies underwent bilateral laser treatment; the mean number of laser burns per eye was 1084 (SD 351; range 490-2231) using a power of 200-700 $\mathrm{mW}$ and duration of 200-300 ms. The duration of treatment varied between 35 and $90 \mathrm{~min}$ in total with a mean treatment time $55 \mathrm{~min}$.

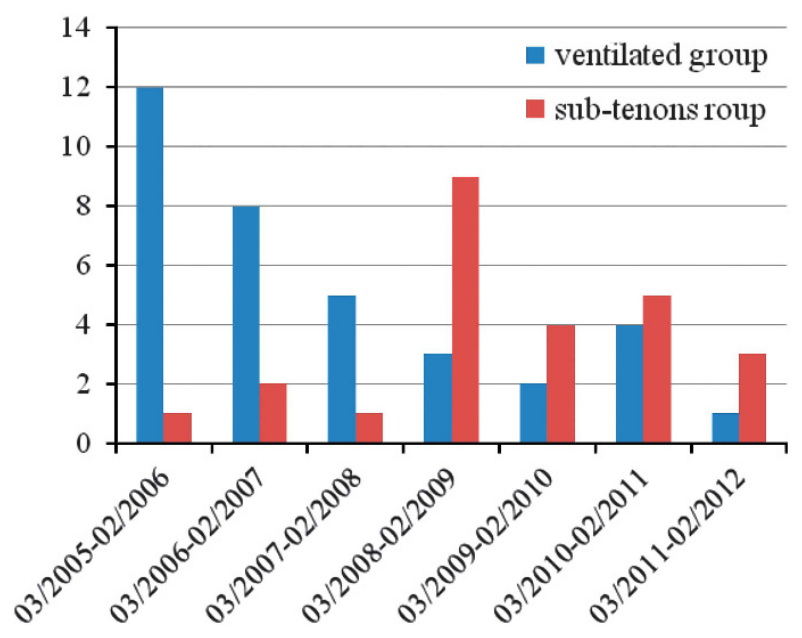

Figure 1 Number of babies treated for ROP using oral or rectal sedation with sub-tenon anaesthesia and general anaesthetic between March 2005 and March 2012.

In all, 3 of the $62(8 \%)$ required re-treatment due to progression of the disease: two of these babies had been treated using intravenous sedation, the third had received treatment using sub-tenon anaesthesia. After re-treatment, the ROP in these three cases regressed without cicatricial sequelae.

\section{Pain scores}

Pain scores were available for 19 babies from sub-tenon group (Table 3 ). The mean baseline pain score was 0.6 
(SD 1.2; range 0-4). The mean pain score during the procedure ranged between 0.5 and 6.2 with the average score of 2.7 (SD 1.7). The mean change in the pain score from the baseline was 2.2 (SD 1.5; range -0.5 to 5.5). The lowest and highest individual pain scores recorded during procedure were 0 and 9 , respectively. No baby in the sub-tenon group (including eight subjects with unknown pain score) developed severe cardiorespiratory instability requiring emergency intubation and ventilation during or immediately after the treatment.

Several of the babies being treated had high peak pain scores-in the $8 \mathrm{~s}$ and $9 \mathrm{~s}$ but these were not persistent as indicated by their mean pain score. When a baby was measured as having a high pain score and was felt to be tolerating the procedure poorly, the laser treatment was paused and supportive measures such as re-swaddling, increasing the supplemental oxygen concentration and oral sucrose were given. In every case the baby settled with these measures and it was not necessary to give intravenous sedation or intubate the baby. Once the laser treatment was restarted, additional topical anaesthesia was given, the laser power was reduced to the minimum effective and/or a different retinal location was treated. Laser treatment was completed in all cases.

There was no statistically significant correlation between the mean pain score and duration of treatment ( $\rho=0.31 ; P=0.09)$, number of laser burns ( $\rho=0.32$; $P=0.09)$, or PMA of the baby at the time of treatment $(\rho=0.38 ; P=0.052)$.

\section{Discussion}

Most treatments for ROP are needed at 34-38 postmenstrual weeks and, at this stage of the neonatal period, the babies have usually been extubated and are having respiratory support and supplemental oxygen provided by CPAP or nasal cannulae. ${ }^{7-9}$ Intravenous sedation in neonates causes respiratory depression, necessitating endotracheal intubation and ventilation-re-intubation is not without risk and can cause acute trauma to the mouth, nose, larynx, and pharynx with the additional risk of hypoxia and bradycardia during the procedure.

Table 2 Characteristics of the babies who underwent laser treatment for ROP between March 2005 and March 2012

\begin{tabular}{|c|c|c|c|}
\hline ROP stage & Ventilated babies $(\mathrm{N}=35)$ & Sub-tenon anaesthesia $(\mathrm{N}=27)$ & P-value \\
\hline Zone2: stage 2 plus & 30 & 19 & 0.2 \\
\hline Zone2: stage 3 plus & 5 & 8 & 0.2 \\
\hline Mean gestational age (weeks) & $25^{+1}\left(\right.$ range $\left.23^{+1}-29^{+6}\right)$ & $25^{+2}$ (range $23-27^{+3}$ ) & 0.09 \\
\hline Mean birth weight (g) & 676 (SD 174; range 450-1422) & 776 (SD 143; range 450-1200) & 0.001 \\
\hline Mean PMA at treatment (weeks) & $37\left(\right.$ range $33^{+4}-44^{+6}$ ) & $37^{+2}\left(\right.$ range $\left.33^{+4}-42^{+2}\right)$ & 0.068 \\
\hline
\end{tabular}

Table 3 Characteristics, treatment detail and pain scores of the group of patients who underwent laser treatment under sub-tenon anaesthesia with oral or rectal sedation

\begin{tabular}{|c|c|c|c|c|c|c|c|c|c|c|}
\hline $\begin{array}{l}\text { Subject } \\
\text { number }\end{array}$ & $\begin{array}{l}\text { Gestational } \\
\text { age }(w+d)\end{array}$ & $\begin{array}{c}\text { Birth } \\
\text { weight }(g)\end{array}$ & $\begin{array}{c}\text { PMA at } \\
\text { treatment } \\
(w+d)\end{array}$ & $\begin{array}{c}\text { Baseline } \\
\text { pain score }\end{array}$ & $\begin{array}{l}\text { Range of } \\
\text { pain score }\end{array}$ & $\begin{array}{l}\text { Mean } \\
\text { pain } \\
\text { score }\end{array}$ & $\begin{array}{l}\text { Mean change } \\
\text { in pain score }\end{array}$ & $\begin{array}{c}\text { Duration of } \\
\text { treatment (min) }\end{array}$ & $\begin{array}{c}\text { Number of } \\
\text { laser burns } \\
\text { (right eye) }\end{array}$ & $\begin{array}{c}\text { Number of } \\
\text { laser burns } \\
\text { (left eye) }\end{array}$ \\
\hline 1 & $26+4$ & 720 & $33+5$ & 0 & $3-6$ & 5.5 & 5.5 & 50 & 1344 & 1213 \\
\hline 2 & 27 & 830 & $39+3$ & 0 & $0-3$ & 1.8 & 1.8 & 60 & 961 & 975 \\
\hline 3 & $23+3$ & 450 & $36+4$ & 0 & $0-8$ & 4.6 & 4.6 & 55 & 864 & 695 \\
\hline 4 & 26 & 900 & $35+5$ & 0 & $4-5$ & 4.6 & 4.6 & 40 & 1161 & 1404 \\
\hline 5 & $27+3$ & 940 & $40+1$ & 0 & 0-9 & 3 & 3 & 70 & 1153 & 1049 \\
\hline 6 & $25+2$ & 730 & $38+3$ & 0 & $0-1$ & 0.5 & 0.5 & 60 & 1043 & 943 \\
\hline 7 & $26+4$ & 972 & $37+6$ & 0 & $0-5$ & 3.2 & 3.2 & 35 & 870 & 900 \\
\hline 8 & 26 & 888 & $42+2$ & 0 & $1-3$ & 2.2 & 2.2 & 50 & 871 & 957 \\
\hline 9 & $25+4$ & 840 & $36+3$ & 0 & $0-1$ & 0.5 & 0.5 & 35 & 1152 & 951 \\
\hline 10 & $25+2$ & 675 & $40+4$ & 0 & $1-5$ & 2.4 & 2.4 & 50 & 931 & 1021 \\
\hline 11 & 27 & 1200 & $33+4$ & 2 & $2-7$ & 4.5 & 2.5 & 60 & 1265 & 1135 \\
\hline 12 & 24 & 740 & $35+3$ & 4 & 5-8 & 6.2 & 2.2 & 40 & 805 & 841 \\
\hline 14 & $24+6$ & 754 & $37+6$ & 0 & $0-4$ & 0.5 & 0.5 & 70 & 1582 & 1290 \\
\hline 15 & 24 & 790 & $39+1$ & 0 & $0-2$ & 1.3 & 1.3 & 60 & 1252 & 989 \\
\hline 16 & $24+4$ & 776 & $36+6$ & 2 & $0-3$ & 1.5 & -0.5 & 90 & 2205 & 1850 \\
\hline 17 & $23+5$ & 560 & $35+5$ & 3 & $1-3$ & 1.6 & 1.4 & 45 & 1188 & 1841 \\
\hline 18 & $25+3$ & 810 & $36+4$ & 0 & $0-5$ & 2 & 2 & 65 & 1131 & 911 \\
\hline 19 & $25+1$ & 705 & $38+4$ & 0 & $0-4$ & 1.6 & 1.6 & 60 & 1848 & 1572 \\
\hline
\end{tabular}


Many infants requiring ROP treatment have evolving lung disease; re-intubation can be a significant retrograde step in their progress with further lung injury caused by the ventilator. Sometimes a prolonged period of ventilation with additional therapies is required before extubation can be attempted. Psychologically, for the parents, re-intubation is felt to be a backward step in their baby's progress. It is well recognised that neonates perceive pain and produce stress response to painful stimuli that may lead to life-threatening episodes of cardiorespiratory instability. ${ }^{3,10}$ There is also a growing evidence that pain in premature babies can result in longterm emotional and behavioural problems, consequently neonatologists working in the NICU recognise the importance of using pharmacological and nonpharmacological therapies that provide effective pain prevention when undertaking any procedure. ${ }^{11,12}$

The baby's physiological response to laser treatment for ROP under sub-tenon anaesthesia using the cardiorespiratory index (CRI) has previously been assessed. ${ }^{4}$ The CRI was demonstrated to be similar in babies who have laser treatment under sub-tenon anaesthesia, general anaesthesia, and intravenous sedation. ${ }^{3,4}$ The advantage of the using N-PASS system in this study is that both physiological and behavioural indicators of pain in the neonate are assessed. The behavioural response changes with maturity and the N-PASS score can be adjusted to PMA.5,13

In our study, the mean pain score during laser treatment in the sub-tenon group (2.7 SD 1.8) was significantly lower than those previously reported during ROP screening (7.5) or the acute pain during heel-stick procedure (3.93).6,14 The pain caused by laser treatment lasted up to $90 \mathrm{~min}$, but prolonged post-operative pain ranging from 4.75 to 7.11 has been measured in term neonates in the week following general surgery. ${ }^{5}$ We conclude that the pain associated with laser treatment under sub-tenon anaesthesia is within an acceptable level. Moreover, no baby suffered a prolonged desaturation or bradycardia requiring emergency endotracheal intubation.

The successful outcome of the laser treatment was not compromised by the use of sub-tenon anaesthesia but, in our opinion, the movement of the eye and the baby during treatment does make the procedure technically more difficult to perform. We did not compare the duration of treatment between groups but it is likely to have been longer in the sub-tenon group because of the short breaks taken during treatment to allow the baby to rest and settle.

Sub-tenon anaesthesia with oral/rectal sedation offers practical advantages over intravenous sedation and has become the method of choice in our unit over the 7-year period of use. We now treat ROP as a 'day-case' transfer from other neonatal units; the avoidance of intubation allows neonatal ambulance transport with a neonatal nurse rather than neonatologist.

This is a retrospective study limited by a relatively small sample size and lack of a control group. A major limitation is the lack of pain score data for 8 of the 27 babies in the sub-tenon group. Activity in the neonatal unit is unpredictable and it was not possible to have an additional member of staff in the treatment room to facilitate N-PASS scoring for these eight cases. There is no evidence in the records to suggest that these eight babies tolerated the procedure differently than the others and none developed significant cardiorespiratory instability requiring emergency intubation and ventilation. Although no pain score data is available for these babies, their inclusion in the study illustrates how our preference for sub-tenon anaesthesia has changed over the 7-year period.

Despite these limitations, our study indicates that laser treatment for ROP under sub-tenon anaesthesia is safe and well tolerated. However, the management of ROP requires a multidisciplinary approach; the neonatal team should carry out a pretreatment assessment and a joint decision should be made regarding the most suitable anaesthetic for each baby.

\section{Summary}

What was known before

- Only two units in the UK regularly use sub-tenon anaesthesia with oral/rectal sedation

- The cardiorespiratory effects of ROP laser treatment under sub-tenon anaesthesia have been evaluated previously, the acceptability of the technique in terms of pain control has not.

What this study adds

- This study assessed the tolerability and outcomes of laser treatment for ROP under sub-tenon anaesthetic with oral/rectal sedation using a reliable multidimensional and internationally accepted tool for assessment of neonatal pain (N-PASS).

\section{Conflict of interest}

The authors declare no conflict of interest.

\section{References}

1 Chen SD, Sundaram V, Wilkinson A, Patel CK. Variation in anaesthesia for the laser treatment of retinopathy of prematurity-a survey of ophthalmologists in the UK. Eye (Lond) 2007; 21(8): 1033-1036.

2 Jalali S, Azad R, Trehan HS, Dogra MR, Gopal L, Narendran V. Technical aspects of laser treatment for acute retinopathy 
of prematurity under topical anesthesia. Indian J Ophthalmol 2010; 58(6): 509-515.

3 Hartrey R. Anaesthesia for the laser treatment of neonates with retinopathy of prematurity. Eye (Lond) 2007; 21(8): 1025-1027.

4 Parulekar MV, Chen SD, Patel CK. Sub-tenon's local anaesthesia for the treatment of retinopathy of prematurity with diode laser. Eye (Lond) 2008; 22(3): 375-379.

5 Hummel P, Puchalski M, Creech SD, Weiss MG. Clinical reliability and validity of the N-PASS: neonatal pain, agitation and sedation scale with prolonged pain. J Perinatol 2008; 28(1): 55-60.

6 Hummel P, Lawlor-Klean P, Weiss MG. Validity and reliability of the N-PASS assessment tool with acute pain. I Perinatol 2010; 30(7): 474-478.

7 Royal College of Paediatrics and Child Health, Royal College of Ophthalmologists British Association of Perinatal Medicine \& BLISS: Guideline for the Screening and Treatment of Retinopathy of Prematurity 2008.

8 Early Treatment for Retinopathy of Prematurity Cooperative G. Revised indications for the treatment of retinopathy of prematurity: results of the early treatment for retinopathy of prematurity randomized trial. Arch Ophthalmol 2003; 121(12): 1684-1694.
9 Multicenter trial of cryotherapy for retinopathy of prematurity: preliminary results. Cryotherapy for Retinopathy of Prematurity Cooperative Group. Pediatrics 1988; 81(5): 697-706.

10 Haigh PM, Chiswick ML, O'Donoghue EP. Retinopathy of prematurity: systemic complications associated with different anaesthetic techniques at treatment. $\mathrm{Br} J$ Ophthalmol 1997; 81(4): 283-287.

11 Porter FL, Grunau RE, Anand KJ. Long-term effects of pain in infants. J Dev Behav Pediatr 1999; 20(4): 253-261.

12 Maroney DI. Recognizing the potential effect of stress and trauma on premature infants in the NICU: how are outcomes affected? J Perinatol 2003; 23(8): 679-683

13 American Academy of Pediatrics; Committee on Fetus and Newborn; Canadian Paediatric Society; Fetus and Newborn Committee. Prevention and management of pain in the neonate. An update. Adv Neonatal Care 2007; 7(3): 151-160.

14 O'Sullivan A, O'Connor M, Brosnahan D, McCreery K, Dempsey EM. Sweeten, soother and swaddle for retinopathy of prematurity screening: a randomised placebo controlled trial. Arch Dis Child Fetal Neonatal Ed 2010; 95(6): F419-F422. 